\title{
THERMAL CONDUCTIVITY OF POLYIMIDE/CARBON NANOFILLER BLENDS
}

\author{
S. Ghose ${ }^{1}$, K.A. Watson², D.M. Delozier ${ }^{2}$, D.C. Working ${ }^{3}$, J.W. Connell ${ }^{3}$, J.G. Smith ${ }^{3}$, Y.P. Sun ${ }^{4}$ and Y. Lin $^{4}$ \\ ${ }^{1}$ NASA Postdoctoral Fellow at NASA LaRC, Hampton, VA 23681 \\ ${ }^{2}$ National Institute of Aerospace, Hampton, VA 23666-6147 \\ ${ }^{3}$ NASA Langley Research Center, Hampton, VA 23681-2199 \\ ${ }^{4}$ Dept of Chemistry, Clemson University, Clemson, SC 26934-0973
}

\begin{abstract}
In efforts to improve the thermal conductivity (TC) of Ultem ${ }^{\mathrm{TM}} 1000$, it was compounded with three carbon based nano-fillers. Multiwalled carbon nanotubes (MWCNT), vapor grown carbon nanofibers (CNF) and expanded graphite (EG) were investigated. Ribbons were extruded to form samples in which the nano-fillers were aligned. Samples were also fabricated by compression molding in which the nano-fillers were randomly oriented. The thermal properties were evaluated by DSC and TGA, and the mechanical properties of the aligned samples were determined by tensile testing. The degree of dispersion and alignment of the nanoparticles were investigated with high-resolution scanning electron microscopy. The thermal conductivity of the samples was measured in both the direction of alignment as well as perpendicular to that direction using the Nanoflash technique. The results of this study will be presented.
\end{abstract}

Keywords: multiwalled carbon nanotubes, carbon nanofibers, expanded graphite, Ultem $1000^{\mathrm{TM}}$

This paper is work of the U. S. Government and is not subject to copyright protection in the U.S.

* To whom correspondence should be addressed: john.w.connell@nasa.gov, (757) 864-4264

\section{INTRODUCTION}

Combining polymers with an organic or inorganic phase to produce a polymer composite is common in the production and processing of modern plastics. Recently, the use of nanoscale fillers to prepare polymer nanocomposites (PNC) have been investigated to augment the properties of polymers. PNCs exhibit significant enhancements in certain properties at a far lower concentration than their conventional micro or macro counterparts. Layered clay, expanded graphite, carbon nanofibers and carbon nanotubes are some of the common nanoparticles used in making PNCs.

Carbon nanofibers (CNF) are widely used as reinforcements for polymers in numerous high-technology applications because of their excellent electrical and thermal properties, high specific tensile strength and modulus [1], improved heat distortion temperatures and increased electromagnetic shielding. CNFs have been used as reinforcements for various thermoplastics [2 - 7].Additionally, CNFs are generally economically more attractive than carbon nanotubes because of their lower manufacturing costs. Graphite is another material that is commonly used as a filler in polymers with excellent thermal and electrical properties. With surface treatment of expanded graphite (EG), its dispersion in a polymer matrix results in composites with excellent mechanical and electrical properties and high TC. In addition, the material is presently two orders of magnitude less expensive than carbon nanotubes [8]. Carbon nanotube (CNT)-based composites are being studied intensively due to the unique physical/mechanical properties of CNTs. CNTs are thought of as the ultimate carbon fibers, and are expected to have high mechanical and electrical properties and ultra high thermal conductivity [9, 10]. When CNTs are dispersed in polymeric materials, an interconnecting network is formed which provides a conductive pathway for electrical and/or thermal current to flow. In electrical conductivity the mechanism involves a flow of electrons whereas for TC the process of conduction occurs via phonon transfer. Various methods have been attempted for achieving good dispersion of CNTs in the polymer [11 - 14]. Theory predicts the TC $(\kappa)$ of carbon nanotubes at room temperature is as high as $\sim 6600 \mathrm{~W} / \mathrm{mK}$ [15]. The experimental value of 3000 $\mathrm{W} / \mathrm{mK}$ for the TC of an individual multiwalled carbon nanotube (MWCNT) at room temperature has been reported [16]. This value is significantly higher than that of known thermally conducting materials like diamond (up to $2300 \mathrm{~W} / \mathrm{mK}$ ) and graphite (up to 1960 $\mathrm{W} / \mathrm{mK}$ ). Although enhancement of TC has been observed in CNT suspensions [17-18], in PNCs the improvement in TC has always been lower than the rule-of-mixture values.

ULTEM $^{\mathrm{TM}}$ was chosen for use as the host resin for trials with the various nanoparticles because the resin is an amorphous thermoplastic polyetherimide offering good melt processability, outstanding high heat resistance, high strength, modulus and broad chemical resistance. Melt compounding was chosen as the method to disperse the nanoparticles in ULTEM ${ }^{\circ}$. Melt mixing was followed by extrusion of the nanocomposite through a suitable die and subsequent drawing leading to continuous ribbons of nanocomposites with substantial orientation of the nanoparticles in the flow direction. The samples were characterized using differential scanning calorimetry, thermogravimetric analysis, high resolution scanning electron microscopy, mechanical tester and thermal conductivity analyzer. The preparation and characterization of samples containing various loadings of CNTs, CNFs and EGs are discussed. 


\section{EXPERIMENTAL}

2.1 Materials Ultem ${ }^{\mathrm{TM}} 1000$ (GE Plastics) was chosen as the polymer matrix and was used as received. MWCNTs, VGE-S16, were procured from the University of Kentucky. CNF, Pyrograph - III - PR-24 HHT was obtained from Applied Sciences, Inc and EG (Grade 3775) was received from Asbury Carbons. The graphite already had the galleries expanded.

2.2 Processing of Ultem ${ }^{\mathrm{TM}} 1000$ with nanofillers Ultem ${ }^{\mathrm{TM}} 1000$ was compounded with MWCNTs, CNFs and EGs in a 30 cc internal mixer for $3 \mathrm{~h}$ at $25 \mathrm{rpm}, 325{ }^{\circ} \mathrm{C}$ under $\mathrm{N}_{2}$ purge at various weight loadings. Upon completion of mixing the material was ground in a grinder using a $5.5 \mathrm{~mm}$ screen. Samples were then extruded through a Laboratory Mixing Extruder at barrel temperature of $210-215{ }^{\circ} \mathrm{C}$ and a die temperature of $350-365^{\circ} \mathrm{C}$ in the form of a continuous ribbon that was cut into pieces, stacked on one side of a mold and the remainder of the mold filled with Ultem ${ }^{\mathrm{TM}}$ pellets. The stacked ribbons were compression molded at $270{ }^{\circ} \mathrm{C}, 1.72 \mathrm{MPa}$ for $3 \mathrm{~h}$. The molded samples were then sliced using a low speed saw with a diamond wafering blade. Unoriented samples were made using a Laboratory Mixing Molder. A rough blend of materials was added to the mixing bowl of LMM kept at $360{ }^{\circ} \mathrm{C}$ for $0.5 \mathrm{~h}$. It was then dynamically pressed and then static pressed to degas, before passing through the nozzle orifice into the rectangular mold kept at $360{ }^{\circ} \mathrm{C}$. The material was then manually compressed at a force of $\sim 4.5 \mathrm{kN}$ and set under pressure from the ram while being air cooled.

2.3 Characterization High-resolution SEM images were obtained using a Hitachi S-5200 field emission scanning electron microscope (FE-SEM) equipped with a "through-the-lens" secondary electron detector. Thin-film tensile properties were determined according to ASTM D882 using either four or five specimens (0.51 cm wide) per test conditions using an Eaton Model 3397-139 11.4 kg load cell on a Sintech 2 test frame. The test specimen gauge length was $5.1 \mathrm{~cm}$ and the crosshead speed for film testing was $0.51 \mathrm{~cm} / \mathrm{minute}$. TC of the molded samples as well as ribbons was measured using a Netzsch LFA 447 NanoFlash according to ASTM E1461. Samples sizes of $1 \mathrm{~cm} \times 1 \mathrm{~cm}$ were sprayed with a thin layer of graphite (for uniform thermal adsorption), which may be easily rinsed away by solvent (e.g., methanol). Pyrex (TC 1.09 W/mK, Cp 0.76 J/gk) was used as the reference.

\section{RESULTS AND DISCUSSION}

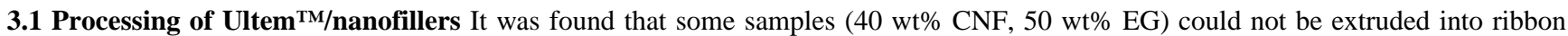
due to either their high melt viscosity or the increased thermal conductivity that led to additional heating in the feeding region of the extruder. The primary purpose of extrusion was to try and align the nanofillers in the direction of flow. Stacked ribbons were molded and samples were obtained by cutting the molded block. In this way samples were obtained with alignment both parallel and perpendicular to the direction of conductivity measurement.

3.2 HRSEM of extruded ribbons Figures 1(a) and (b) are the HRSEM images at higher MWCNT loading. The MWCNTs appeared well dispersed throughout the polymer and are aligned in the direction of extrusion (denoted by the arrow).

3.3. Mechanical properties of extruded ribbons Mechanical properties were measured on Ultem ${ }^{\mathrm{TM}} / \mathrm{nanofiller}^{\mathrm{c}}$ composites with the results shown in Table 1. The strips used for testing were cut from ribbons that were prepared from extrusion; hence the nanofillers are somewhat in alignment in the direction of the stress. The $5 \mathrm{wt} \%$ MWCNT solution-mixed sample and the $40 \mathrm{wt} \%$ EG melt mixed sample did not provide ribbons of sufficient quality for mechanical testing. The other results should be viewed with care because the measurement of the ribbon thickness is not accurate due to uneven ribbon surfaces. As expected, with increased filler loading level, the modulus increased and the elongation decreased.

3.4 TC measurements Since the structure of nanotubes is anisotropic in space, the electrical and thermal properties should be different in the longitudinal (parallel to nanotube axis) and transverse (perpendicular to nanotube axis) directions. It has been reported that when CNTs were dispersed in polymers, enhancements in TC were observed [15, 19]. However, the enhanced values are typically below those predicted by the rule of mixtures. One probable reason for this is the existence of interface thermal resistance between the overlaps in the CNT passage leading to a rapid increase in overall thermal resistance [20]. Alignment of nanofillers in the polymer matrix leads to enhancement of TC [21, 22]. Based on the literature survey done so far, it was decided to process samples with significant nanofiller alignment and measure TC both in the direction and perpendicular to the direction of alignment (nanotube axis).

Three types of Ultem ${ }^{\mathrm{TM}} /$ nanofiller samples were measured for TC. These were the extruded ribbon, molded samples cut perpendicular to flow direction, and samples with no alignment. For the extruded ribbons the TC was measured perpendicular to the

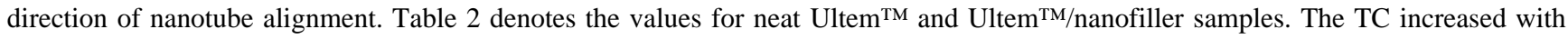
increase in loading level of nanofillers. The highest TC was observed in the $30 \mathrm{wt} \% \mathrm{CNF}$ samples and the conductivity was increased by $180 \%$ with respect to the neat material. The second set of samples was the molded samples where the TC was measured in the direction of nanofiller alignment. This data has also been shown in a plot (Figure 2). The TC of the samples were observed to be significantly greater in the direction of alignment compared to those that were perpendicular to the direction of alignment. The MWCNT samples at 20 wt\% loading exhibited an 11.5-fold increase in TC relative to neat Ultem ${ }^{\mathrm{TM}}$ whereas the CNF samples loaded at $30 \mathrm{wt} \%$ showed a 15 fold increase. The largest increase was exhibited by $40 \mathrm{wt} \%$ loading of EG samples which showed a 38-fold increase. The data indicates that the nanofillers, when aligned, form a network that successfully conducts heat by enabling a more efficient phonon transfer from one filler particle to another. Finally when it comes to the unoriented samples, it was found that $40 \mathrm{wt} \%$ CNF filled samples showed a 10 -fold increase while the $50 \mathrm{wt} \%$ EG sample showed a 19-fold improvement in TC. These results prove conclusively that alignment of the nanofillers in the polymer matrix significantly raises the TC of the samples. However, unaligned samples also show a significant improvement and may be useful in applications when it is not possible to achieve nanoparticles alignment in the desired direction. 


\section{SUMMARY}

Ultem $^{\mathrm{TM}}$ was mixed with three different carbon-based nanofillers in efforts to increase the thermal conductivity of the polymer. HRSEM revealed significant alignment of the nanofillers in the extruded samples. TC measurements were made both in the direction and perpendicular to the direction of alignment of nanofillers as well as for unaligned samples. It was found that the largest improvement in TC was achieved in the case of aligned samples when the measurement was performed in the direction of alignment. Unaligned samples also showed a significant improvement in TC and may be useful in applications when it is not possible to align the nanofiller in the desired direction..

\section{ACKNOWLEDGEMENT}

The authors would like to gratefully acknowledge Prof. Lawrence T. Drzal of Michigan State University for his valuable discussion. They would also like to thank Asbury Carbons for providing the EG and Tom Hughes of Applied Sciences, Inc. for providing the CNFs. Many thanks to Dr Craig M. Thompson, National Institute of Aerospace for helpful discussions.

\section{FIGURES AND TABLES}

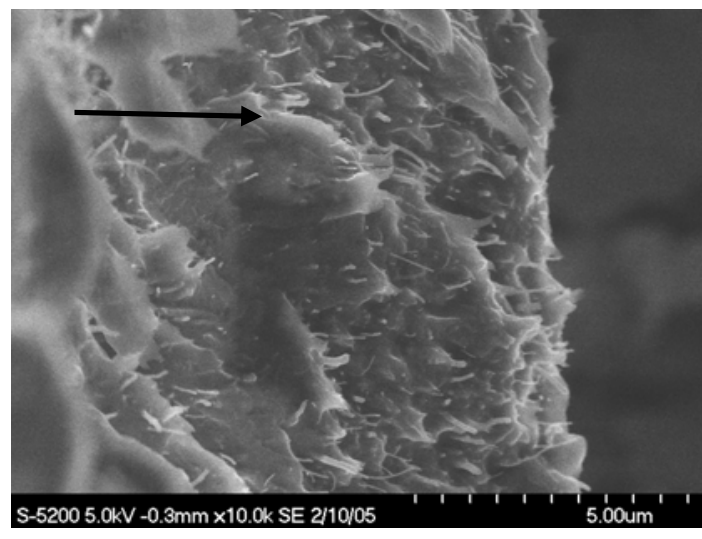

(a) $10 \mathrm{wt} \%$ MWCNTs

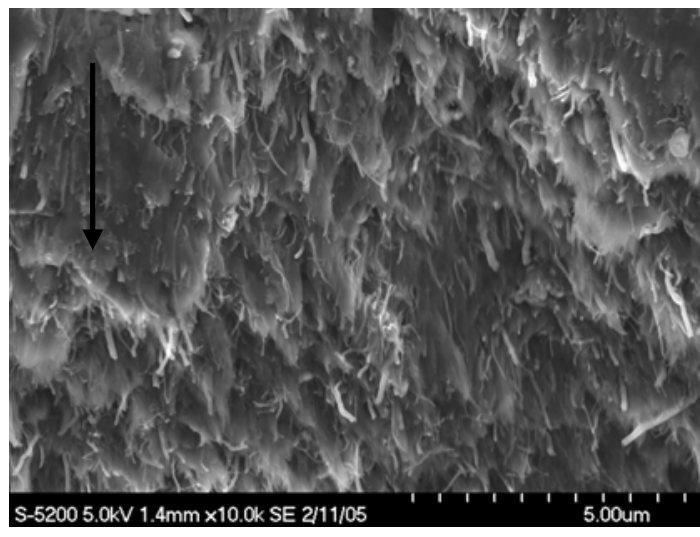

(b) $20 \mathrm{wt} \%$ MWCNTs

Figure 1: HRSEM of Ultem ${ }^{\mathrm{TM}} /$ nanofiller ribbon sample; arrow denotes direction of flow

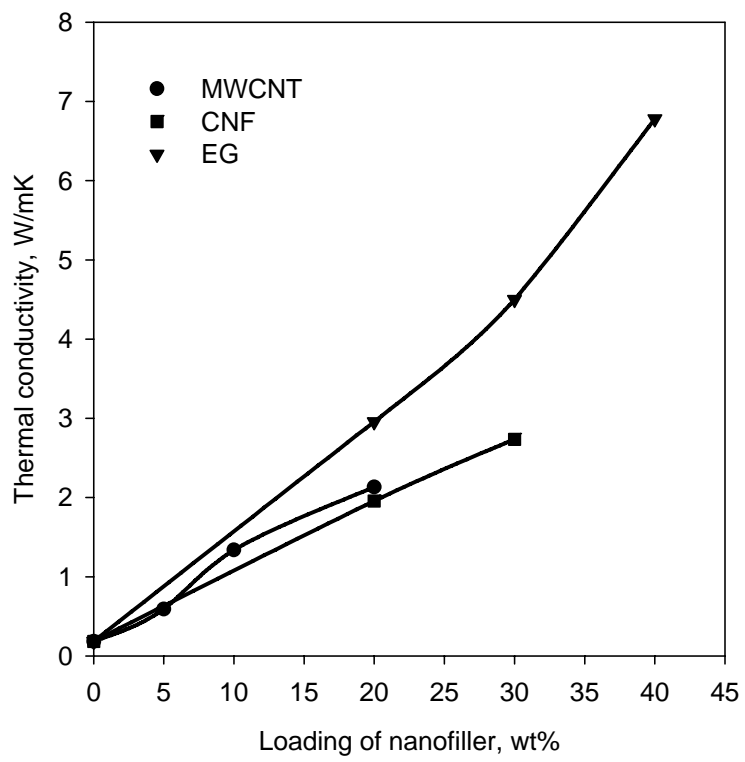

Figure 2: TC of molded Ultem ${ }^{\mathrm{TM}} /$ nanofiller samples; measurement along direction of alignment

Table 1: Mechanical properties of Ultem ${ }^{\mathrm{TM}} /$ nanofiller samples:

\begin{tabular}{|l|l|l|l|}
\hline Sample & $\begin{array}{l}\text { Modulus, } \\
\text { GPa }\end{array}$ & $\begin{array}{l}\text { Strength, } \\
\text { MPa }\end{array}$ & $\begin{array}{l}\text { Elong., } \\
\text { \% }\end{array}$ \\
\hline Ultem ${ }^{\mathrm{TM}}$-- Neat & $1.45 \pm 0.05$ & $49.64 \pm 1.38$ & $16 \pm 11$ \\
\hline Ultem $^{\mathrm{TM}}$, 5 wt\% MWCNT & $2.56 \pm 0.12$ & $91.70 \pm 6.20$ & $7 \pm 0.5$ \\
\hline Ultem $^{\mathrm{TM}}$, 10 wt\% MWCNT & $2.95 \pm 0.17$ & $72.39 \pm 5.51$ & $4 \pm 1$ \\
\hline Ultem $^{\mathrm{TM}}$, 20 wt\% MWCNT & $3.50 \pm 0.30$ & $60.67 \pm 11.72$ & $2 \pm .4$ \\
\hline
\end{tabular}




\begin{tabular}{|l|l|l|l|}
\hline Ultem $^{\mathrm{TM}}, 20 \mathrm{wt} \% \mathrm{CNF}$ & $2.83 \pm 0.30$ & $48.26 \pm 6.89$ & $2 \pm 0.3$ \\
\hline Ultem $^{\mathrm{TM}}, 30 \mathrm{wt} \% \mathrm{CNF}$ & $3.76 \pm 0.16$ & $78.60 \pm 5.52$ & $3 \pm 0.6$ \\
\hline Ultem $^{\mathrm{TM}}, 20 \mathrm{wt} \% \mathrm{EG}$ & $5.40 \pm 0.2$ & $80.00 \pm 13.00$ & $2 \pm 0.4$ \\
\hline Ultem $^{\mathrm{TM}}, 30 \mathrm{wt} \% \mathrm{EG}$ & $7.6 \pm 0.3$ & $96.5 \pm 19.00$ & $2 \pm 0.5$ \\
\hline Ultem $^{\mathrm{TM}}, 40 \mathrm{wt} \% \mathrm{EG}$ & -- & -- & -- \\
\hline
\end{tabular}

Table 2: Thermal conductivity of Ultem ${ }^{\mathrm{TM}} /$ nanofiller extruded ribbons:

\begin{tabular}{|c|c|c|c|}
\hline Sample & $\begin{array}{l}\mathrm{TC}, \mathrm{W} / \mathrm{mK} \\
\text { perpendicular to } \\
\text { alignment }\end{array}$ & $\begin{array}{l}\mathrm{TC}, \mathrm{W} / \mathrm{mK} \\
\text { parallel to } \\
\text { alignment }\end{array}$ & $\begin{array}{l}\text { TC, W/mK } \\
\text { random } \\
\text { alignment }\end{array}$ \\
\hline Neat Ultem $^{\mathrm{TM}}$ & 0.172 & 0.184 & 0.172 \\
\hline Ultem $^{\mathrm{TM}}, 5$ wt\% MWCNT & 0.229 & 0.592 & --- \\
\hline Ultem $^{\mathrm{TM}}, 10 \mathrm{wt} \% \mathrm{MWCNT}$ & 0.272 & 1.337 & --- \\
\hline Ultem $^{\mathrm{TM}}, 20$ wt\% MWCNT & 0.389 & 2.132 & 0.500 \\
\hline Ultem $^{\mathrm{TM}}, 20 \mathrm{wt} \% \mathrm{CNF}$ & 0.364 & 2.034 & --- \\
\hline Ultem $^{\mathrm{TM}}, 30 \mathrm{wt} \% \mathrm{CNF}$ & 0.463 & 2.785 & $\begin{array}{c}-- \\
-\end{array}$ \\
\hline Ultem $^{\mathrm{TM}}, 40 \mathrm{wt} \% \mathrm{CNF}$ & --- & $\cdots$ & 1.184 \\
\hline Ultem $^{\mathrm{TM}}, 20 \mathrm{wt} \% \mathrm{EG}$ & 0.278 & 2.982 & 0.660 \\
\hline Ultem $^{\mathrm{TM}}, 30$ wt\% EG & 0.315 & 4.727 & 0.973 \\
\hline Ultem $^{\mathrm{TM}}, 40 \mathrm{wt} \% \mathrm{EG}$ & 0.387 & 6.852 & 2.144 \\
\hline
\end{tabular}

\section{REFERENCES}

1. E. Hammel, X. Tang, M. Trampert, T. Schmitt, K. Mauthner, A. Eder and P. Potschke, Carbon, 42, 1153-1158 (2004).

2. K. Lozano, S. Yang and Q. Zeng, J. Appl. Poly. Sc., 93, 155-162 (2004).

3. R.J. Kuriger, M.K. Alam, D.P. Anderson and R.L. Jacobsen, Composites, Part A, $\underline{33}$, 53-62 (2002).

4. K. Lozano, J. Bonilla-Rios and E.V. Barrera, J. Appl. Poly. Sc., 79, 125-133 (2001).

5. O.S. Carneiro, J.A. Covas, C.A. Bernardo, G. Caldeira, F.W.J. Van Hattum, J.M. Ting, R.L. Alig and M.L. Lake; Composites Sc. Tech., $\underline{58}, 401-407$ (1998).

6. R.T. Pogue, J. Ye, D.A. Klosterman, A.S. Glass and R.P. Chartoff, Composites: Part A, 29, 1273 (1998).

7. C.A. Cooper, D. Ravich, D. Lips, J. Mayer and H.D. Wagner, Composites Sc. Tech., 62, 1105 (2002).

8. L.T. Drzal and H. Fukushima, Unites States Patent Application Publication, Pub No. US20040127621 (2004).

9. X. Gao, L. Liu, Q. Guo, J. Shi and G. Zhai, Materials Letters, 모, 3062-3065 (2005).

10. K.T. Lau and D. Hui, Composites Part B: Engineering, 33, 263-277 (2002).

11. C. Park, Z. Ounaies, K.A. Watson, R.E. Crooks, J.G. Smith Jr., S.E. Lowther, J.W. Connell, E.J. Siochi, J.S. Harrison and T.L. St. Clair, Chem. Phys. Lett.; 364, 303 (2002).

12. J.G. Smith Jr., J.W. Connell and P.M. Hergenrother, Soc. Adv. Matl and Proc. Eng. Proc.; 46 : 510 (2001).

13. R. Haggenmueller, H.H. Gommans, A.G. Rinzler, J.E. Fischer and K.I. Winey, Chem Phys Lett; 330,219 (2000).

14. R. Andrews, D. Jacques, M. Minot and T. Rantell, Macromol. Mater. Eng., 287(6), 395 (2002).

15. C.H. Liu, H. Huang, Y. Wu and S.S. Fan, Appl. Phys. Lett, 84, 4248-4250 (2004).

16. P. Kim, L. Shi, A. Majumdar and P.L. McEuen, Phys. Rev. Lett. 87 (21), 215502 (2001).

17. Y. J. Hwang, Y.C. Ahn, H.S. Shin, C.G. Lee, G.T. Kim, H.S. Park and J.K. Lee, Current Appl. Phys. article in press (2005).

18. S.U.S. Choi, Z.G. Zhang, W. Yu, F.E. Lockwood and E.A. Grulke, Appl. Phys. Lett, 79, 2252-2254 (2001).

19. H. Huang, C. Liu, Y. Wu and S. Fan, Adv. Mater (Communications), 17, 1652-1656 (2005).

20. S.T. Huxtable, D.G. Cahill, S. Shenogin. L. Xue, R. Ozisik, P. Barone, M. Usrey, M.S. Strano, G. Siddons, M. Shim and P. Keblinski, Nat. Mater., 11, 731-734 (2003).

21.Q. Gong Q, Z. Li, X. Bai, D. Li, Y. Zhao and J. Liang, Mater. Sc. Eng.A 384, 209 (2004).

22. Y.M. Chen and J.M. Ting, Carbon, 느, 359-362 (2002). 